\title{
VARIA
}

\section{ALONSO GUTIÉRREZ, UN PINTOR DESCONOCIDO, RECUPERADO}

La publicación del importante repertorio de documentos reunidos por Mercedes Agulló y Cobo y Teresa Baratech, a lo largo de décadas de paciente labor en los archivos madrileños, especialmente en el de Protocolos y en los parroquiales ${ }^{1}$, proporciona a cuantos nos ocupamos de la pintura madrileña, un impagable caudal de noticias y precisiones que enriquecen nuestro conocimiento y aclaran muchísimos interrogantes, contribuyendo de modo decisivo a perfilar un panorama lleno aún de lagunas y problemas.

Quisiera solamente señalar, en esta ocasión, que un documento allí publicado parece resolver un problema atributivo que viene, desde hace años, preocupando a quienes nos ocupamos de la historia del bodegón español. En repetidas ocasiones se ha exhibido y reproducido una soberbia Vanitas de colección particular madrileña, cuya firma abreviada « $\mathrm{AL}^{\circ}$ GV.» no era posible leer de modo preciso y convincente, y cuya excelente calidad sorprendía a todos ${ }^{2}$.

Creo que su autor puede identificarse, con cierta seguridad, con el Alonso Gutiérrez «pintor, vecino de Madrid» que el día 10 de Octubre de 1636 hace testamento ${ }^{3}$.

Al estudiar el hermoso lienzo en 1983, hube de indicar que «mientras su firma no haya sido leída e interpretada de una manera convincente, el cuadro debe permanecer como anónimo. Se trata, seguramente, de una obra castellana, realizada hacia 1630-40 con una fuerte influencia riberesca».

Este Alonso Gutiérrez, que el documento revela y de quien nada más sabemos, es artista vivo precisamente en esos años, y de los términos de su testamento se deduce que conocía a Ribera, pues uno de los lienzos que había dejado en prenda a una Inés de Rosas, por un préstamo de 50 reales, figura precisamente «un San Francisco, copia de Jusepe de Ribera» ${ }^{4}$.

\footnotetext{
${ }^{1}$ Mercedes Agulló y Cobo y María Teresa Baratech Zalama, Documentos para la historia de la Pintura Española, II, Madrid, Museo del Prado, 1996.

${ }^{2}$ Se reprodujo por vez primera, con una insostenible atribución a Alonso Vázquez, en R. Torres Martín, La naturaleza muerta en la pintura española, Barcelona, 1971, p. 65, lám. 45, y se expuso como anónima en diversas ocasiones, especialmente en Pintura española de Bodegones y Floreros de 1600 a Goya, Madrid, 1983, n. ${ }^{\circ} 47$. Véase también: Alfonso E. Pérez Sánchez, La Nature Morte espagnole du xviieme siècle a Goya, Friburgo, 1987, pp. 78-79.

${ }^{3}$ Agulló-Baratech, ob. cit., 1996, p. 46.

${ }^{4}$ Id. id.
} 


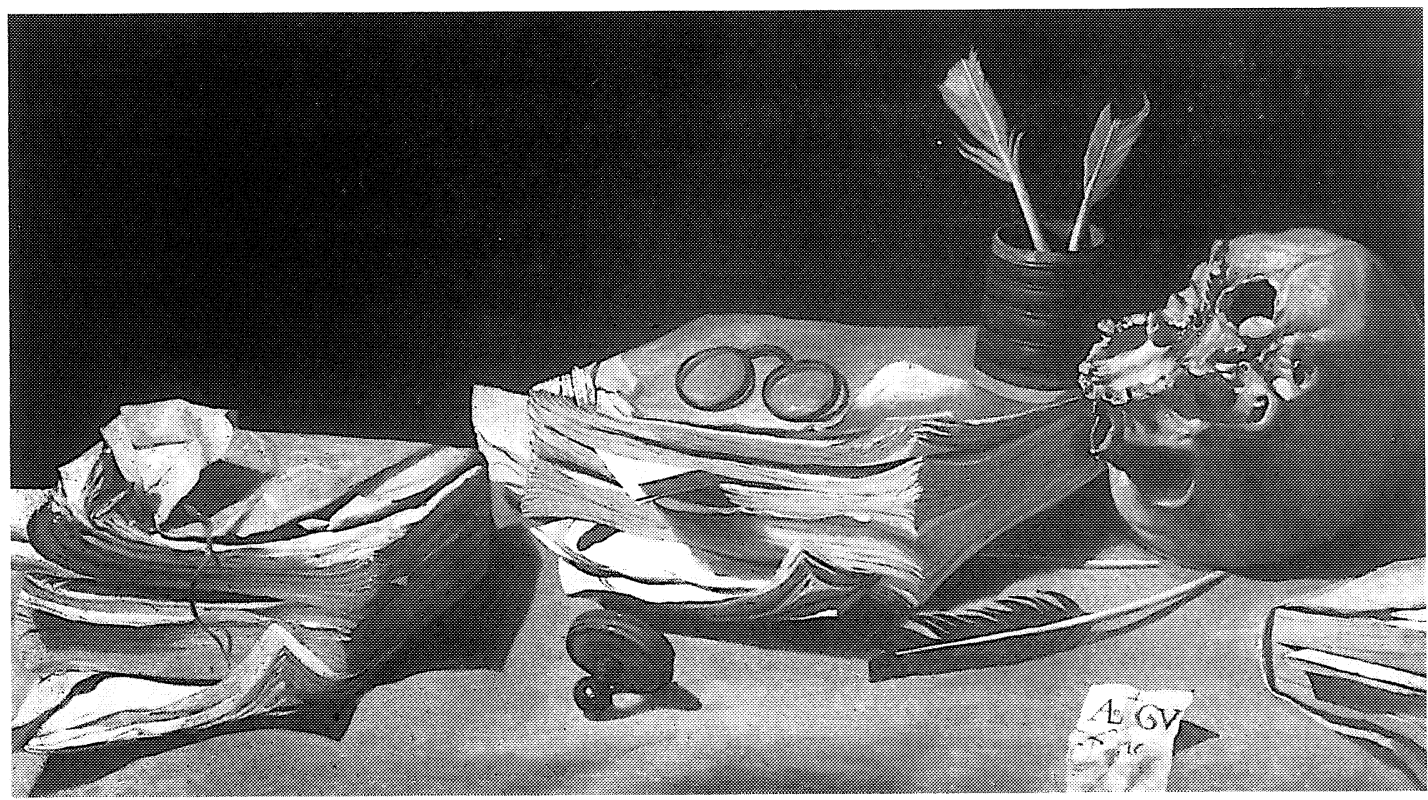

Alonso Gutiérrez. «Vanitas». Madrid, colección particular.

De su relación con el medio de los pintores madrileños cultivadores del bodegón da testimonio, también, la mención de que Antonio Ponce, bodegonista hoy bien conocido ${ }^{5}$, le debía catorce reales lo que indica familiaridad o intereses comunes.

Es poco para poder afirmar de modo tajante que el lienzo sea de su mano, pero son datos suficientemente significativos para que, al menos, pueda y deba, en lo sucesivo, recogerse y citarse bajo el nombre de éste Alonso Gutiérrez con un punto de interrogación si se desea extremar la prudencia.

La calidad evidente de la pintura, de tan intenso naturalismo tenebrista y tan apurada perfección en el tratamiento de la materia inanimada, hace lamentar que no poseamos, por ahora, otras obras de su mano.

De la lectura del testamento se deduce que, como tantos otros modestos pintores madrileños de su tiempo, hubo de cultivar preferentemente el género religioso, copiando modelos ajenos y no sólo de Ribera. Como otro bodegonista revelado en los últimos tiempos, Francisco de Burgos Mantilla $^{6}$, Gutiérrez copió obras de Tiziano - un Cristo y una Nuestra Señora- atestiguando una vez más la vigencia de los modelos piadosos del gran veneciano, siempre presentes en la pintura madrileña, y tampoco desdeñaba trabajos de restauración o de «aderezo», como el que hizo a un retrato de los Reyes, de un Don Andrés Gutiérrez de Aro, por un importe de cuarenta reales. Se perfila, pues, como un modesto práctico de la pintura, quizás sin demasiadas aspiraciones, pero dueño, si efectivamente el lienzo es suyo, de una excelente técnica y de un poderoso sentido de lo real, aprendido sin duda en los modelos del más riguroso tenebrismo del primer tercio del siglo.

Alfonso E. PÉREZ SÁNCHEZ Universidad Conplutense

${ }^{5}$ Sobre Antonio Ponce (1608-1677), véase el catálogo de la Exposición Spanish Still Life from Velázquez to Goya, Londres, National Gallery, 1995, preparado por W. Jordan y P. Cherry.

${ }^{6}$ M. Agulló y A. E. Pérez Sánchez, «Francisco de Burgos Mantilla», Boletín del Seminario de Estudios de Arte y Arqueología, Universidad de Valladolid, 1981, pp. 359-382. 